\title{
Breath-Holding Spells Associated With Significant Bradycardia: Successful Treatment With Permanent Pacemaker Implantation
}

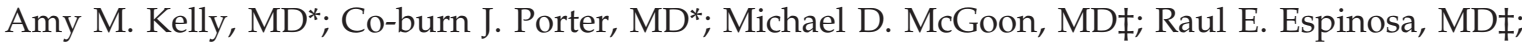

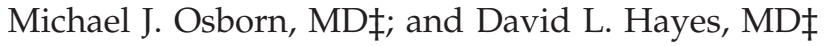

\begin{abstract}
Objective. To determine whether children with pallid breath-holding spells associated with bradycardia can be treated safely and successfully with permanent pacemaker implantation.

Methods. The records of pediatric patients who had apparent breath-holding spells and associated bradycardia and were treated with permanent pacemaker implantation were reviewed.

Results. Ten pediatric patients with apparent breathholding spells associated with bradycardia were treated with a permanent ventricular demand pacemaker at the Mayo Clinic between 1985 and 1995. Patients had onset of symptoms between ages 6 days and 12 months and presented for evaluation between ages 12 months and 5 years. Duration of spells was $\mathbf{1 5}$ seconds to $\mathbf{1 0}$ minutes. Medications to prevent spells were unsuccessful. Electrocardiograms documented asystolic pauses of 1.7 to 24 seconds (mean: 11.9 seconds). Permanent ventricular demand pacemakers were implanted at 10 months to 5 years of age (median: 14.5 months): 9 endocardial and 1 epicardial. Three patients required pacemaker revision. At follow-up of 38 to 170 months (median: 65.5), 5 patients had complete resolution of spells, 2 had only mild color change without loss of consciousness or seizure activity, and 3 continued to have minor brief spells.

Conclusions. Permanent pacemaker therapy for children with pallid breath-holding spells associated with severe bradycardia is safe, efficacious, and warranted. Pediatrics 2001;108:698-702; bradycardia, breath-holding spells, pacemaker.
\end{abstract}

ABBREVIATIONS. ECG, electrocardiogram; EEG, electroencephalogram.

$\mathrm{B}$ reath-holding spells are widely known in the pediatric population. They usually are harmless, albeit distressing for the parents, and resolve with time. We report on 10 patients who presented with symptoms consistent with breathholding episodes. These events were more severe, prolonged, and incapacitating to the families than typical spells, and additional evaluation revealed that they were associated with significant bradycardia. We decided to implant permanent pacemakers in an attempt to alleviate or eliminate symptoms. ${ }^{1,2}$

From the *Department of Pediatric and Adolescent Medicine and the $\neq \mathrm{Di}$ vision of Cardiovascular Diseases and Internal Medicine, Mayo Clinic, Rochester, Minnesota.

Received for publication Jun 13, 2000; accepted Mar 9, 2001.

Reprint requests to (C.J.P.) Department of Pediatric and Adolescent Medicine, Mayo Clinic, 200 First St SW, Rochester, MN 55905.

PEDIATRICS (ISSN 0031 4005). Copyright (C) 2001 by the American Academy of Pediatrics.
This article reviews these patients and assesses the long-term outcome of pacemaker treatment in this population.

\section{METHODS}

Ten patients presented to the Mayo Clinic between 1985 and 1995 for further evaluation of apparent breath-holding spells or seizures (Table 1). Patients were identified by pacemaker records and Mayo Clinic master sheet summaries. Table 1 summarizes the patient characteristics, age at onset, symptoms during spells, age at pacemaker implantation, and course after pacemaker implantation. Their subsequent course was reviewed to evaluate shortand long-term outcomes. Follow-up information was obtained from the Mayo Clinic outpatient and inpatient records and from correspondence with referring physicians and parents.

\section{RESULTS}

The records of 10 patients who received permanent ventricular demand pacemaker implantation for bradycardia associated with breath-holding spells were reviewed. Patients had onset of symptoms between ages 6 days and 12 months and at the time of pacemaker implantation were between ages 10 months and 5 years. The time between onset of symptoms and pacemaker implantation ranged between 2 months and 4.6 years. There were 7 girls and 3 boys. Symptoms of spells included tonic-clonic activity in 6, cyanosis in 8 , prolonged apnea in 4 , and status epilepticus in $1 ; 2$ patients required cardiopulmonary resuscitation, 1 of them on several occasions. Duration of spells was 15 seconds to 10 minutes. All episodes were provoked by anger or painful stimuli. Medications to prevent spells were administered to 8 patients and included anticonvulsants in 5, anticholinergics in 4, and theophylline in 2. All medication trials were unsuccessful. Review of standard 12-lead electrocardiogram (ECG) for all patients did not reveal any abnormalities of QT or QRS intervals. Electrocardiographic monitoring was done in all patients during symptomatic episodes and documented systolic pauses of 1.7 to 24 seconds (mean: 11.9 seconds; median: 14.2 seconds). All patients were treated with permanent ventricular demand pacemaker implantation, 9 endocardial and 1 epicardial. Patients were followed for 38 to 170 months (median: 65.5 months).

Four patients required pacemaker revision. One patient (patient 7) began having spells again after a year and subsequently was noted to have intermittent failure to capture. Another patient (patient 1) had his pacemaker removed 4 years after implantation because of possible pacemaker-related intestinal symptoms and lack of syncopal episodes for more than a year. He required pacemaker reimplantation 4 
TABLE 1. Demographics of Patients Treated With Pacemakers for Breath-Holding Spells

\begin{tabular}{|c|c|c|c|c|c|c|c|c|}
\hline Patient & $\begin{array}{l}\text { Age at } \\
\text { Onset }\end{array}$ & Gender & Symptoms & Tx Before PM & $\begin{array}{l}\text { Length of } \\
\text { Pause(s) }\end{array}$ & $\begin{array}{l}\text { Age at PM } \\
\text { Implant }\end{array}$ & $\begin{array}{l}\text { Length of } \\
\text { FU (mo) }\end{array}$ & $\begin{array}{l}\text { Course After } \\
\text { PM Implant }\end{array}$ \\
\hline 1 & $2 \mathrm{wk}$ & M & $\begin{array}{l}\text { Clonic activity, } \\
\text { cyanosis, } \\
\text { pallor }\end{array}$ & $\begin{array}{l}\text { Normal EEG, CT, } \\
\text { phenobarbital, } \\
\text { clonazepam, } \\
\text { phenytoin, } \\
\text { primidone }\end{array}$ & 15 & $12 \mathrm{mo}$ & 170 & $\begin{array}{l}\text { Resolution of spells, PM } \\
\text { removed and } \\
\text { subsequent recurrence } \\
\text { of spells }\end{array}$ \\
\hline 2 & $6 \mathrm{mo}$ & F & $\begin{array}{l}\text { Cyanosis, } \\
\text { apnea, CPR }\end{array}$ & Normal EEG & 1.7 & $12 \mathrm{mo}$ & 135 & Resolution of spells \\
\hline 3 & $8 \mathrm{mo}$ & F & $\begin{array}{l}\text { Apnea, CPR } \\
\times 5 \text {, eyes } \\
\text { rolled back }\end{array}$ & $\begin{array}{l}\text { Normal EEG } \times 5 \text {, } \\
\text { negative head CT } \\
\times 2, \text { propantheline, } \\
\text { theophylline }\end{array}$ & $6.8-7.4$ & $10 \mathrm{mo}$ & 129 & $\begin{array}{l}\text { Had mild spells the first } \\
\text { year after PM } \\
\text { Revision of PM for } \\
\text { intermittent failure to } \\
\text { capture at } 3 \text { mo }\end{array}$ \\
\hline 4 & $4 \mathrm{mo}$ & $\mathrm{F}$ & $\begin{array}{l}\text { LOC, arching } \\
\text { of back }\end{array}$ & $\begin{array}{l}\text { Propantheline, } \\
\text { belladonna and } \\
\text { phenobarbital }\end{array}$ & 8.6 & $4 y$ & 95 & $\begin{array}{l}\text { Brief episodes but no } \\
\text { LOC, PM replaced } \\
\text { after } 9 \text { y for lead } \\
\text { retraction and battery } \\
\text { EOL }\end{array}$ \\
\hline $5^{*}$ & $4 \mathrm{mo}$ & $\mathrm{F}$ & $\begin{array}{l}\text { Tonic-clonic } \\
\text { activity, } \\
\text { LOC, apnea, } \\
\text { cyanosis, } \\
\text { status } \\
\text { epilepticus }\end{array}$ & $\begin{array}{l}\text { Normal EEG, CT, } \\
\text { phenobarbital, } \\
\text { carbamazepine, IV } \\
\text { diazepam for } \\
\text { status epilepticus }\end{array}$ & $13-15$ & $5 y$ & 68 & Resolution of spells \\
\hline $6^{*}$ & $12 \mathrm{mo}$ & $\mathrm{F}$ & $\begin{array}{l}\text { Tonic-clonic } \\
\text { activity, } \\
\text { cyanosis }\end{array}$ & $\begin{array}{l}\text { Normal EEG, } \\
\text { belladonna and } \\
\text { phenobarbital }\end{array}$ & 24 & $16 \mathrm{mo}$ & 63 & $\begin{array}{l}\text { Occasionally turns blue, } \\
\text { but no LOC }\end{array}$ \\
\hline 7 & $12 \mathrm{mo}$ & $\mathrm{F}$ & $\begin{array}{l}\text { Tonic-clonic } \\
\text { activity, } \\
\text { LOC, apnea }\end{array}$ & $\begin{array}{l}\text { Theophylline, normal } \\
\text { EEG }\end{array}$ & $2.2-4.7$ & $19 \mathrm{mo}$ & 59 & $\begin{array}{l}\text { Resolution of spells, } \\
\text { recurrence of spells } \\
\text { secondary to } \\
\text { intermittent failure to } \\
\text { capture, resolution } \\
\text { with PM replacement }\end{array}$ \\
\hline 8 & $11 \mathrm{mo}$ & $\mathrm{F}$ & Cyanosis, LOC & None & 20 & $13 \mathrm{mo}$ & 45 & Resolution of spells \\
\hline 9 & $7 \mathrm{mo}$ & M & $\begin{array}{l}\text { Tonic-clonic } \\
\text { activity, } \\
\text { apnea, } \\
\text { cyanosis }\end{array}$ & $\begin{array}{l}\text { Normal EEG, } \\
\text { positive OCT, } \\
\text { atropine drops }\end{array}$ & $4.2-4.4$ & $12 \mathrm{mo}$ & 39 & $\begin{array}{l}\text { Continued to have } \\
\text { intermittent spells, } \\
\text { last spell } 12 / 97, \\
\text { currently takes } \\
\text { propranolol }\end{array}$ \\
\hline 10 & 6 days & M & $\begin{array}{l}\text { Cyanosis, tonic } \\
\text { activity }\end{array}$ & $\begin{array}{l}\text { Normal EEG, } \\
\text { carbamazepine }\end{array}$ & $\begin{array}{l}\text { HR to } 36 \\
\text { beats / } \\
\text { min }\end{array}$ & 2 y 5 mo & 38 & $\begin{array}{l}\text { Continued spells with } \\
\text { decreased frequency } \\
\text { and severity, } \\
\text { currently takes } \\
\text { propranolol }\end{array}$ \\
\hline
\end{tabular}

CPR indicates cardiopulmonary resuscitation; CT, computed tomogram; EEG, electroencephalogram; EOL, end of life; FU, follow-up; HR, heart rate; IV, intravenous; LOC, loss of consciousness; OCT, ocular compression test; PM, pacemaker; Tx, evaluation and treatment.

* Sisters.

months after removal for recurrence of significant spells; during 1 episode he passed out and fell down a flight of stairs. His spells resolved after pacemaker reimplantation. The third patient (patient 3) required revision secondary to intermittent failure to capture. The fourth patient (patient 4) required pacemaker replacement 9 years after initial implantation for lead retraction and pacemaker generator end of life.

After pacemaker implantation, 5 patients had immediate and complete resolution of spells. Two had spells that consisted only of mild color change without loss of consciousness or seizure activity, 1 continued to have mild brief spells for the first year that subsequently resolved, and 2 of the male patients continue to have intermittent moderate spells, which are less frequent and less severe than those before pacemaker implantation. We believe that these are due to episodes of hypotension. Both of these patients currently receive $\beta$-adrenergic receptor blocker therapy, which has been shown to be effective in many adolescents with syncopal episodes. ${ }^{3}$ The remaining 8 patients are symptom- free and are not taking any medications. Telephone follow-up of all 10 patients revealed that these patients are active, healthy children who are in their normal, age-appropriate grade in school and have developed normally. Activities include competitive swimming and hockey for 2 of the patients. During reviewer telephone conversations, parents unanimously reported that they would have "absolutely no reservation recommending this treatment to other parents" and noted that the placement of the pacemaker "changed our lives for the better."

\section{Sample Cases}

\section{Patient 3}

Patient 3 began having symptoms at 8 months of age. Her first spell occurred while she was crawling across the floor: suddenly she fell facedown, unconscious on the carpet. She was noted to be blue and apneic. She was shaken and regained consciousness. She began to cry and subsequently went completely 
limp and lost consciousness again for several seconds. The entire episode lasted 60 to 90 seconds. The next day, the patient was feeding and dropped her bottle. She became angry and subsequently became limp. Again she was noted to be blue and apneic, with her eyes rolled back. This episode lasted approximately 30 seconds, and she was taken to the hospital. Results of an electroencephalogram (EEG) and an ECG were normal. During the hospitalization, the patient had 2 more episodes with loss of consciousness, and, during 1, the mother noted a faint, slow pulse. Subsequently, she was transferred to a tertiary care center where she had another episode witnessed by medical personnel. An EEG, an ECG, and a computed tomogram of the head all were normal. It was recommended that the child be treated with phenobarbital, but the mother refused because she did not believe that the child had epilepsy. A few days later, the patient had a severe spell that required cardiopulmonary resuscitation. Subsequently, an echocardiogram was done and found to be normal. An ambulatory ECG reportedly showed episodes of both high and low heart rates during apnea. During the course of the next few weeks, the patient required cardiopulmonary resuscitation on 4 additional occasions during spells; she was hospitalized 5 times and had 3 more normal EEGs, a second normal head computed tomogram, 2 more normal echocardiograms, a pneumogram sleep study, which occasionally showed heart rates of $50 \mathrm{bpm}$, and a negative study of the upper gastrointestinal tract. She was treated with propantheline and theophylline, with some minor improvement, and was sent home with an apnea monitor.

Approximately 2 months after her first spell, she was evaluated at our institution. A repeat ECG when the patient was hospitalized at our institution revealed significant asystole with 3 systolic beats over a total of 18 seconds (Fig 1). A permanent Pacesetter Programalith 241-6 VVI transvenous pacemaker (Pacesetter, Inc, Sylmar, CA) was implanted and subsequently required revision 3 months later because of intermittent failure to capture. She had occasional mild spells the first year after implantation, which were significantly shorter in duration. The mother reported that their whole lifestyle changed for the better after the pacemaker was implanted. The par- ents did not have to be constantly vigilant and could feel comfortable leaving her with babysitters and taking her to day care, whereas before pacemaker implantation only the parents could care for her. Currently, the patient is $11^{1 / 2}$ years old and entering the sixth grade. She does well in school and participates on a competitive swim team.

\section{Patient 5}

Patient 5 began having symptoms at 4 months of age. Whenever she was angry or hurt, she would begin to cry, stop abruptly, turn blue, and then become pale. Her arms would stiffen, her back would arch, and she would lose consciousness. The episodes were associated with tonic-clonic activity lasting up to 10 minutes. Despite normal EEGs, she was treated with phenobarbital because of the tonicclonic nature of these spells. She continued to take phenobarbital for approximately $1 \frac{1}{2}$ years but continued to have spells. As a result of a personality change perceived by the family, which they related to the initiation of medication, the phenobarbital was discontinued. One week after stopping the medication, she had a significant spell that was preceded by crying and apparent breath-holding and followed by seizure activity. Subsequently, she was treated with carbamazepine for $1 \frac{1 / 2}{2}$ years. During this period, she continued to have spells associated with cyanosis and loss of consciousness but without seizure activity. She was weaned off the carbamazepine, and approximately 4 days later she began crying and had an apparent breath-holding spell followed by seizure activity, which evolved into status epilepticus and required multiple intravenous doses of diazepam and eventually was aborted with a loading dose of phenobarbital. Computed tomography of the head and an EEG were normal. The carbamazepine was restarted, but she continued to have syncopal episodes without subsequent seizure activity. The family history was significant for older and younger female siblings with similar spells and a paternal aunt with a history of spells during childhood. The patient presented to our institution at 5 years of age. An ambulatory ECG revealed symptomatic episodes associated with 15 seconds of asystole. As a result of this, a Medtronic Minix 8330 VVI transvenous pacing system (Medtronic, Inc, Minneapolis, MN) was im-

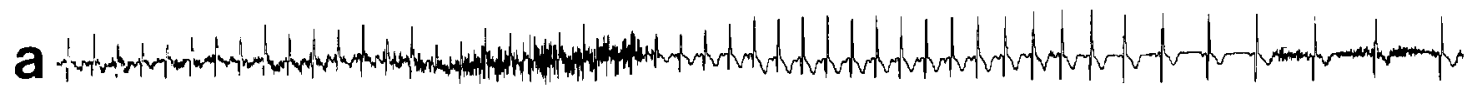
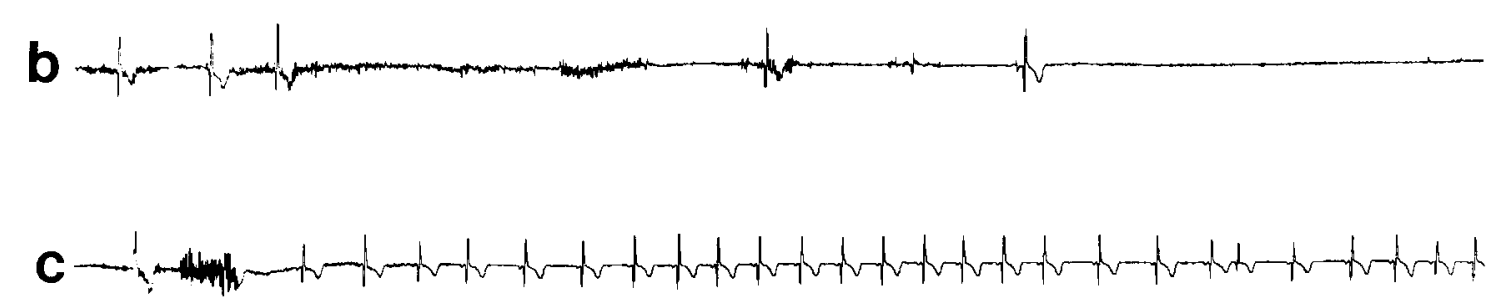

Fig 1. Asystole associated with breath-holding spell. A, Patient begins breath-holding. B, Beginning of asystolic periods separated by 3 systolic beats. Artifact secondary to tonic-clonic activity. C, Resolution of spell with resumption of normal rhythm. 
planted. In addition, the patient was treated with propranolol (10 mg given orally 3 times a day). This medication was started in an attempt to prevent the initiation of spells and to treat her in a similar manner to adolescents who have been treated successfully for neurocardiogenic syncope. ${ }^{3}$ After pacemaker placement, the parents noted that the patient would "try" to have spells, turning slightly dusky, but she would not progress to loss of consciousness or seizure activity. After showing significant improvement, she was weaned off the propranolol without showing recurrence of symptoms. The patient is 10 years old and in the fifth grade. She is developmentally normal, participates in soccer and softball, and is not taking any medication.

\section{DISCUSSION}

As demonstrated by our patient population, apparent breath-holding spells can be associated with periods of asystole. By preventing asystole with permanent pacemaker implantation, it seems that one can prevent the distressing symptoms associated with these episodes, including seizures. Breath-holding spells have long been discussed in the pediatric literature, with the earliest descriptions dating back to the early 1600s. ${ }^{4}$ Episodes consistent with the diagnosis of breath-holding spells usually are triggered by a stimulus such as anger or pain and can consist of cyanosis, apnea, changes in postural tone, and even tonic-clonic activity. Benign breath-holding spells occur in up to $27 \%$ of healthy children. Severe breath-holding spells have been reported to occur in $0.1 \%$ to $4.6 \%$ of healthy children. ${ }^{4,5}$ Breath-holding spells are slightly more common in boys than in girls. ${ }^{4,5}$ In our population, significant breath-holding spells were less frequent in boys, and boys also seem to have more refractory symptoms that did not respond as well to pacemaker implantation. The onset of spells usually occurs between the ages of 6 and 18 months, with the frequency and severity of these episodes peaking during the second and third years of life. Frequency of spells can vary from multiple episodes a day to once a year. The greatest proportion of children with severe breath-holding spells experience multiple episodes per week, with as many as one third of children having multiple episodes per day. ${ }^{4}$ In our group, frequency of spells ranged from multiple episodes a week to 30 episodes a day. Ninety percent of children with breath-holding spells have complete resolution of spells by 6 years of age. ${ }^{4-8}$

A landmark paper in 1967 by Lombroso and Lerman $^{5}$ classified breath-holding spells into 2 main types: cyanotic and pallid. Cyanotic breath-holding spells are more common and usually are triggered by a stimulus such as anger or frustration. After becoming cyanotic, the child becomes limp and loses consciousness. Children may regain consciousness immediately or remain sleepy for several hours after the episode. In contrast to cyanotic breath-holding spells, pallid breath-holding spells are precipitated by little crying, and loss of consciousness is rapid. 5,6 The major clinical observation is pallor, and the most common precipitator, if there is one, is pain. 5,6 The pathophysiology of pallid breath-holding is different, with loss of consciousness being preceded by 1 to several seconds of asystole. ${ }^{5,6}$ These children have been shown to have an exaggerated oculocardiac reflex, resulting in asystole in $61 \%$ of the children with pallid breath-holding spells and in only $25 \%$ of the children with cyanotic breath-holding spells. ${ }^{5}$ This finding implies that the underlying mechanism in these spells is mediated by the vagus nerve. ${ }^{8}$ The association between vagal tone and breath-holding spells has led to the investigation of the relationship between pallid breath-holding spells and dysfunction of the autonomic nervous system. Autonomic dysfunction has been implicated as a mechanism underlying childhood pallid breath-holding spells by DiMario et al. ${ }^{8}$

Approximately $15 \%$ of patients with breath-holding spells have some seizure-like activity. 5,6,9 The majority of patients in our series had seizure-like activity associated with their apparent breath-holding spell. The longer the loss of consciousness, the greater the chance of seizure activity, which can progress to status epilepticus, as happened in 1 of our patients. ${ }^{10}$ It is of utmost importance to differentiate breath-holding spells from true epileptic seizure activity. Epileptic episodes usually do not have a consistent preceding stimulus, can occur in sleep or be sleep related, are associated often with incontinence, and usually are associated with an abnormal EEG. Breath-holding spells almost always have an identifiable preceding stimulus, never occur during sleep, are not associated with incontinence, and are associated with a normal EEG. A majority of our patients had received a diagnosis of a seizure disorder and were treated with anticonvulsant medication despite, in some cases, several normal EEGs. Other authors have reported that anticonvulsant drugs often are used inappropriately for these patients. ${ }^{11}$

In 1978, Stephenson ${ }^{11}$ diagnosed reflex anoxic seizures associated with pallid breath-holding spells. Before referral, these patients had received incorrect diagnoses often because the history of provocation was ignored. It is interesting that $72 \%$ of these patients were referred with a diagnosis of epilepsy, and $21 \%$ of these patients had been treated with 1 or more anticonvulsant medications despite the fact that none of the children had abnormal EEGs. In addition, $78 \%$ of the children who had a diagnosis of reflex anoxic seizures had asystole of 2 seconds or longer with ocular compression, and $55 \%$ had asystole of 4 seconds or longer, supporting the idea that these seizures result from vagally mediated cardiac arrest. ${ }^{11}$ In our series, nearly all patients with complicated pallid breath-holding spells had complete resolution of seizures after pacemaker implantation. None of the patients with previous seizure activity continued to require anticonvulsant medication.

Severe bradycardia in children has been associated with acute life-threatening events that require cardiopulmonary resuscitation and with death. ${ }^{12} \mathrm{We}$ believe that significant bradycardia occurs with a heart rate of fewer than 20 beats per minute or asystole greater than 6 seconds. Symptomatic bradycardia remains the most common indication for pace- 
maker implantation in the pediatric population. ${ }^{13,14}$ Cardiac pacing in children has undergone many advances during the last 10 years, and continued development in the area of follow-up has helped in 1) achieving maximum pacing benefit based on the needs of the individual patient, 2) maximizing longevity, and 3) detecting pacemaker malfunction. ${ }^{14}$ In addition, current transvenous pacemaker systems can be implanted with minimal scarring, and patients usually require less than 48 hours in the hospital after implantation.

In general, breath-holding spells are benign disorders that often resolve with time. However, in the complex case with severe and frequent spells that are unresponsive to medication and are associated with seizures, life-threatening bradycardia, or asystole, aggressive intervention should be considered. In such patients, we believe that permanent pacemaker implantation is safe, efficacious, and warranted.

\section{REFERENCES}

1. Sapire DW, Casta A, Safley W, O'Riordan AC, Balsara RK. Vasovagal syncope in children requiring pacemaker implantation. Am Heart J. 1983;106:1406-1411

2. Rein AJ, Simcha A, Ludomirsky A, Appelbaum A, Uretzky G, Tamir I.
Symptomatic sinus bradycardia in infants with structurally normal hearts. J Pediatr. 1985;107:724-727

3. O'Marcaigh AS, MacLellan-Tobert SG, Porter CJ. Tilt-table testing and oral metoprolol therapy in young patients with unexplained syncope. Pediatrics. 1994;93:278-283

4. DiMario FJ Jr. Breath-holding spells in childhood. Am J Dis Child. 1992;146:125-131

5. Lombroso CT, Lerman P. Breathholding spells (cyanotic and pallid infantile syncope). Pediatrics. 1967;39:563-581

6. Evans OB. Breath-holding spells. Pediatr Ann. 1997;26:410-414

7. Laxdal T, Gomez MR, Reiher J. Cyanotic and pallid syncopal attacks in children (breath-holding spells). Dev Med Child Neurol. 1969;11: 755-763

8. DiMario FJ Jr, Chee CM, Berman PH. Pallid breath-holding spells. Evaluation of the autonomic nervous system. Clin Pediatr (Phila). 1990; 29:17-24

9. Gauk EW, Kidd L, Prichard JS. Mechanism of seizures associated with breath-holding spells. N Engl J Med. 1963;268:1436-1441

10. Emery ES. Status epilepticus secondary to breath-holding and pallid syncopal spells. Neurology. 1990;40:859

11. Stephenson JB. Reflex anoxic seizures ('white breath-holding'): nonepileptic vagal attacks. Arch Dis Child. 1978;53:193-200

12. Kelly DH, Pathak A, Meny R. Sudden severe bradycardia in infancy. Pediatr Pulmonol. 1991;10:199-204

13. Gillette PC, Case CL, Oslizlok PC, Zeigler VL, O'Connor AW. Pediatric cardiac pacing. Cardiol Clin. 1992;10:749-754

14. Kugler JD, Danford DA. Pacemakers in children: an update. Am Heart J. 1989;117:665-679

\section{K + PER YEAR!}

According to the Washington-based Association of Research Libraries, the average cost of an annual subscription to an academic journal shot up to $207 \%$ between 1986 and 1999. In response, the number of journals bought by libraries dropped by $6 \%$ over that period. It now costs a remarkable $\$ 17444$ a year to subscribe to Brain Research, a Reed Elsevier title.

Economist. May 12-18, 2001

Editor's Note. And you think Pediatrics is expensive at $\$ 130$ a year! 